\title{
AOIR
}

Selected Papers of \#AoIR2020:

The $21^{\text {st }}$ Annual Conference of the

Association of Internet Researchers

Virtual Event / 27-31 October 2020

\section{FIRM DISCOURSES AND DIGITAL INFRASTRUCTURE PROJECTS}

\author{
Mathieu O'Neil \\ University of Canberra \\ Laure Muselli \\ Telecom Paris \\ Stefano Zacchiroli \\ Université Paris Diderot / Inria \\ Xiaolan Cai \\ University of Canberra \\ Fred Pailler \\ Université de Nantes
}

Author's note. This paper is a snapshot of research conducted in the early months of 2020; it does not represent the final version of our argument.

\section{Background and research question}

IT firms have embraced open licenses and the hacker ethic of self-fulfillment: free and open source software (a.k.a. FOSS or 'digital infrastructure') is now fully integrated into commercial ecosystems. In 2016 the Linux Foundation released its seventh report to celebrate the 25th anniversary of the famous free software kernel. The report noted that the volume of contributions from unpaid developers had fallen to $7.7 \%$, from $11.8 \%$ in $2014 .{ }^{1}$ IT firms invest in FOSS in order (a) to share with other firms, under the leadership of foundations, development costs; (b) to help attract prospective employees in a competitive job market where hiring skilled IT professionals is challenging:

Suggested Citation (APA): O'Neil, M., Muselli, L., Zacchiroli, S., Cai, X., Pailler, F.(2020, October) Firm Discourses and Digital Infrastructure Projects. Paper presented at AolR 2020: The 21th Annual Conference of the Association of Internet Researchers. Virtual Event: AolR. Retrieved from http://spir.aoir.org. 
involvement in FOSS has been integrated into IT firms' HR strategy; and (c) to shape the governance and technical orientation of projects: firm employees participating in or leading FOSS projects may help IT firms create digital infrastructure more suited to the firmware they develop atop this infrastructure. For critical theorists, this represents a shift from an informational capitalism strongly relying on intellectual property to a new digital capitalism which integrates 'openness' into its business model (Birkinbine, 2020; Lund \& Zukerfeld, 2020). These critical accounts do not investigate how the world of FOSS volunteers interacts with commercial ecosystems: are firms developing policies in relation to open source communities, requesting projects conform to certain technical or behavioral standards, for example? If that is the case, to what extent are these strategies successful? To answer, we present a qualitative analysis of firm discourses collected during three open source conferences. We then analyze the email discussion lists of Linux and Firefox (the most widely used open source browser) and search for the occurrence of key firm discourse terms in order to ascertain in what way these discourses are being used by FOSS developers.

\section{Methodology}

\section{Ethnography}

We collected data at three conferences: FOSDEM2019 (Brussels) is strongly developercentric; the 2019 European Open Source Summit (Lyon), was organized by the Linux Foundation to promote international IT firms' marketing; the 2019 Paris Open Source Summit was attended by smaller European IT firms. Researchers attended keynotes and talks based on how firm employee presentation abstracts addressed the firmvolunteer community relationship. Notes were collected according to a predetermined template. Firm discourses were subsequently classified into themes such as 'FOSS in the firm' e.g. Open Source Program Offices (OSPOs), project hosting, performance metrics, business models, human resources, documentation standards, etc.; 'FOSS between firms' e.g. license compliance, trust/neutrality between competitors, safety/security issues, etc.; 'other actors' e.g. foundations, FOSS activists, users, etc.; and 'labour/work issues' e.g. paid/unpaid activities, diversity programs, community management, governance issues, etc. Key terms were developed inductively, based on trends and concepts encountered in the data.

\section{Content analysis}

Data was collected via R using the rvest package between Dec 16, 2019 and Jan 21, 2020. 228,000 emails created between Jan 01, 2018 and April 30, 2019 were collected from the Linux-kernel archives and 13,770 emails created between Jan 1, 2015 and April 30, 2019 from the firefox-dev archives. We then searched these emails for key terms identified in the qualitative phase and performed proximity analyses using qanteda by collecting the words situated immediately before and after these key terms.

\section{Findings and discussion}

We identified three key themes in the IT firm discourses we collected. These highlight norms and practices that serve the goals outlined in our background section, though this purpose is seldom explicit in the discourse itself.

O’Neil, M, et al. (2020, October 28-31). Firm discourses and digital infrastructure projects. Paper presented at AolR 2020: The 201 ${ }^{\text {th }}$ Annual Conference of the Association of Internet Researchers. Dublin, Ireland: AolR. Retrieved from http://spir.aoir.org. 
1-Marketing: marketing should be considered a necessary activity for open source projects, not a 'bad word'. It encompasses branding and design (logos, mascots); helping users identify sponsoring firms; communication using performance indicators (number of contributors, code commits, contributing firms) helps projects attract both developers willing to contribute and corporate users. Highlighting OSPOs, as many firms did in Lyon contributes to the communication strategy, as it emphasizes firm involvement in open source.

2-Security \& safety: these notions highlight concerns about how far technologies can be trusted. Safety refers to the fact that a 'system must run as expected', while security refers to the fact that a 'system cannot be misused'. Safety introduces a new perspective to open source. Security is a major concern for large IT firms, since the open source model has proved vulnerable to security breaches. The Spectre and Meltdown vulnerabilities in the proprietary microcode of Intel CPUs highlighted how ineffective communication between firms and some open source projects was, as their informal structure made it difficult to inform them of breaches. The Heartbleed security breach, caused by a lack of openSSL code review, showed that a cryptography library used by most large end users relied on a community comprising two individuals. Security concerns have prompted IT and end user firms to initiate projects (such as ELISA) aiming to enable the Linux kernel's compliance to safety standards.

3-Diversity: diversity refers to the concern for the representation of social groups amongst large IT firm employees. It is also a concern for access to (paid) work for minorities in projects and communities. Definitions of diversity provided by large IT firms are generally implicit, involving a broad range of meanings, such as 'the possibility for people not to work in a hostile environment' or 'confronting differences without reacting negatively'. Speakers provided tips on how traditional forms of address could be exclusionary ('guys', 'black/white hat'). Firms strove to develop diversity programs aiming to enable traditionally excluded minorities to work within open source projects.

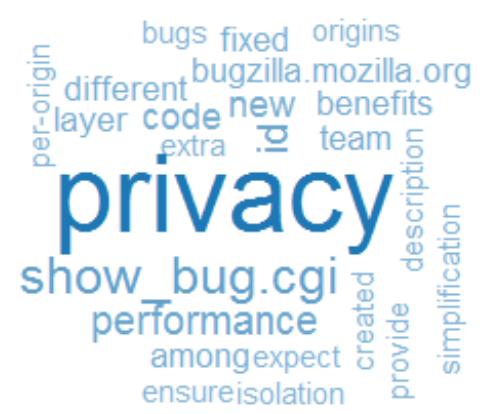

Figure 1. Word cloud of keyword-proximity, Firefox-dev email archive.

O’Neil, M, et al. (2020, October 28-31). Firm discourses and digital infrastructure projects. Paper presented at AolR 2020: The 201 ${ }^{\text {th }}$ Annual Conference of the Association of Internet Researchers. Dublin, Ireland: AolR. Retrieved from http://spir.aoir.org. 


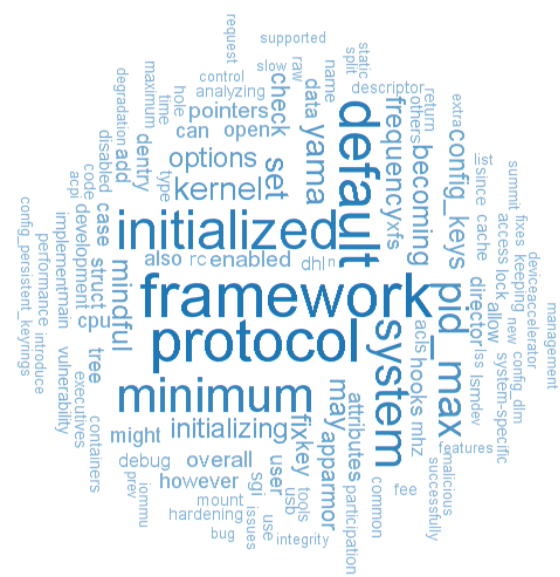

Figure 2. Word cloud of keyword-proximity, Linux-kernel email archive.

We found that 'diversity' and 'marketing' were quasi-absent from email discussions, perhaps reflecting developers' indifference to social inclusion and disapproval of nontechnical topics. In contrast 'security' was omnipresent in both email discussion lists. The semantic environments of this keyword highlights the difference between the traditional not-for-profit status of the Mozilla Foundation $(501 \mathrm{c} / 3)$ and the Linux Foundation's role as an industrial consortium supported by large firms $(501 \mathrm{c} / 6)$ : discussions on the Linux list were technical (e.g. 'security framework initialized', 'wusb host has no security descriptors', etc) whilst those on the Firefox list reflected concerns about user rights and privacy, as can be seen from the word clouds (Figure 1). The only non-technical discourses on the Linux list concerned communications about upcoming Linux Foundation conferences or security events.

\section{Conclusions}

Our quantitative results are exploratory; comparisons with more projects would offer clearer insights. That said, our in-depth analysis of firm discourses about digital infrastructure projects and exploratory analysis of project discussions around these terms show that the FOSS world encompasses a diversity of industrial outlooks. They also highlight the evolution of the role of foundations or 'boundary organizations' (O'Mahony \& Bechky, 2008): whilst foundations used to protect projects from firm interference, some have now wholly been placed in the service of firm efforts to standardize project work, particularly around the key issue of security.

\section{References}

Birkinbine, B. J. (2020) Incorporating the Digital Commons: Corporate Involvement in Free and Open Source Software. London: University of Westminster Press.

Lund, A. \& Zukerfeld, M. (2020) Corporate Capitalism's Use of Openness. Basingstoke: Palgrave Macmillan.

O'Mahony, S. \& Bechky, B.A. (2008). Boundary organizations: Enabling collaboration among unexpected allies. Administrative Science Quarterly, 53, 422-459.

O'Neil, M, et al. (2020, October 28-31). Firm discourses and digital infrastructure projects. Paper presented at AolR 2020: The 201 ${ }^{\text {th }}$ Annual Conference of the Association of Internet Researchers. Dublin, Ireland: AolR. Retrieved from http://spir.aoir.org. 
${ }^{1} \mathrm{https}$ ://www.linuxfoundation.org/press-release/2016/08/the-linux-foundation-releases-development-reporthighlighting-contributions-to-the-linux-kernel-ahead-of-25th-anniversary-of-linux/

O’Neil, M, et al. (2020, October 28-31). Firm discourses and digital infrastructure projects. Paper presented at AolR 2020: The 201 ${ }^{\text {th }}$ Annual Conference of the Association of Internet Researchers. Dublin, Ireland: AolR. Retrieved from http://spir.aoir.org. 